\title{
ROCHAS DO PATRIMÔNIO HISTÓRICO CONSTRUÍDO DE PONTA GROSSA, PR
}

\author{
Antonio Liccardo ${ }^{1}$, Samara Moleta Alessi ${ }^{2}$,Mariane Louro de Lima ${ }^{2}$ \\ 1 - Geólogo, docente - DEGEO - UEPG; 2 - Geógrafa, discente - DEGEO - UEPG \\ aliccardo@uepg.br
}

Resumo: Ponta Grossa (PR) foi fundada em 1862 e se localiza na divisa entre o Primeiro Planalto Paranaense (Embasamento Cristalino) e Segundo Planalto Paranaense (rochas ígneas e sedimentares da Bacia do Paraná), apresentando um patrimônio urbanístico especial, construído a partir da geodiversidade local que é característica. Um levantamento das rochas utilizadas na urbanização do centro antigo do município foi realizado, a partir de um mapa de 1920 e pesquisa bibliográfica correlacionada ao levantamento de campo. O conjunto histórico se constitui de um complexo ferroviário instalado em fins do século XIX, praça matriz e arredores, conforme o mapa que apresenta os limites do município até então. As rochas reconhecidas nesse conjunto são provenientes de antigas pedreiras da região e de outras localidades a partir do possível transporte por trem. Pavimentos antigos, blocos de cantaria e detalhes arquitetônicos das edificações tombadas como patrimônio foram analisados e, entre os resultados, um mapa esquemático foi elaborado compilando os dados disponíveis. Muitas calçadas e construções históricas mostraram informações sobre o passado que presenciaram, mas comumente são negligenciadas como fonte de informação e boa parte vem sendo destruída ou descaracterizada. Este estudo aponta a necessidade de preservação e manutenção adequada em algumas calçadas e outros detalhes arquitetônicos. A informação levantada sobre as rochas presentes nas edificações ou sobre as possíveis áreas fonte dos materiais pode subsidiar ações de restauro ou preservação da memória no planejamento urbano, além de constituir um campo para educação patrimonial.

Palavras Chave: rochas, patrimônio construído, Ponta Grossa

Abstract: STONES OF THE HISTORIC HERITAGE BUILT OF PONTA GROSSA, PR. The city of Ponta Grossa (PR) was founded in 1862 and is located on the border between Paraná Plateau (Crystalline) and Second Plateau of Paraná (sedimentary and igneous rocks of the Paraná Basin), presenting a special urban heritage, built from the local geodiversity. A research about rocks used in the area of old Center was carried out, from a map of 1920 and bibliographical research correlated the field survey. The heritage buildings are constituted by a railway complex installed in the late 19th century, the main church square and its surroundings, as the map used exposes the limits of the municipality (1920). The rocks recognized in this set are from ancient quarries of the region and other places possible coming by train. Antique flooring, masonry blocks and architectural details of old buildings were analyzed and, among the results, a schematic map was put together by compiling available data. Many sidewalks and historical constructions showed information about the past, but commonly are neglected as a source of information and much has been destroyed or mischaracterized. This study points out the need for preservation and proper maintenance on some sidewalks and other architectural details. The information up on the rocks present in the buildings or on carries(possible source areas of materials) can help actions of restoration or memory preservation in urban planning, in addition to be a field for heritage education.

Keywords: dimension stones, cultural heritage, Ponta Grossa

\section{INTRODUÇÃO}

Este estudo busca correlacionar informações obtidas na análise de rochas encontradas em construções do patrimônio histórico de Ponta Grossa, Paraná, com a evolução social e territorial do município. $\mathrm{Na}$ análise do patrimônio construído da maioria das cidades é possível encontrar importantes vestígios sobre o cotidiano e os costumes locais no passado histórico. Dentre estes vestígios, destaca-se o uso de materiais de origem natural que compõem a geodiversidade regional, especificamente rochas que se prestam ao uso arquitetônico. Anteriormente ao surgimento da grande rede de transportes que disponibilizaria materiais provenientes de múltiplas regiões globais, os povos utilizavam os recursos que eram encontrados nas proximidades, ou nos limites de seu sistema de transporte de época, já que as rochas são materiais de grande volume e peso.

$\mathrm{Na}$ análise da cidade de Ponta Grossa, foi considerado o conjunto preservado no centro da cidade para uma caracterização do uso de rochas em sua construção, assim como as possíveis proveniências destes materiais. Para a delimitação do conjunto histórico (não há uma delimitação oficial) foi utilizado um mapa urbano de 1920 (Figura 01), que forneceu os subsídios sobre as edificações e pavimentos desta época e a definição da área de estudo. Em geral o desenvolvimento das cidades ao longo da história no Brasil tem ocorrido a partir de um centro que costuma ser a igreja matriz e sua praça associada. Em Ponta Grossa o surgimento da estrada de ferro e a implantação da estação deslocou o núcleo de irradiação do desenvolvimento.

Ponta Grossa tem sua origem ligada ao tropeirismo desde o século XVIII, mas somente em 1862 foi elevada à cidade. O sistema ferroviário surgiu em Ponta Grossa a partir de 1894, com a primeira estação denominada Estação Paraná, a qual ligava Paranaguá-Curitiba-Ponta Grossa. Ao lado desta estação foi construído o armazém que estocava o material transportado pelos trens. A segunda estação surgiu em 1900, que acabou por extinguir o uso da estação anterior, chamando a atenção por sua construção moderna. Esta fazia a ligação São Paulo-Rio Grande do Sul, com parada obrigatória em Ponta Grossa (GIESBRECHT, 2014). Ambas as estações foram tombadas em 1990 pelo Conselho do Patrimônio Histórico do Paraná, por seu valor histórico e arquitetônico. 


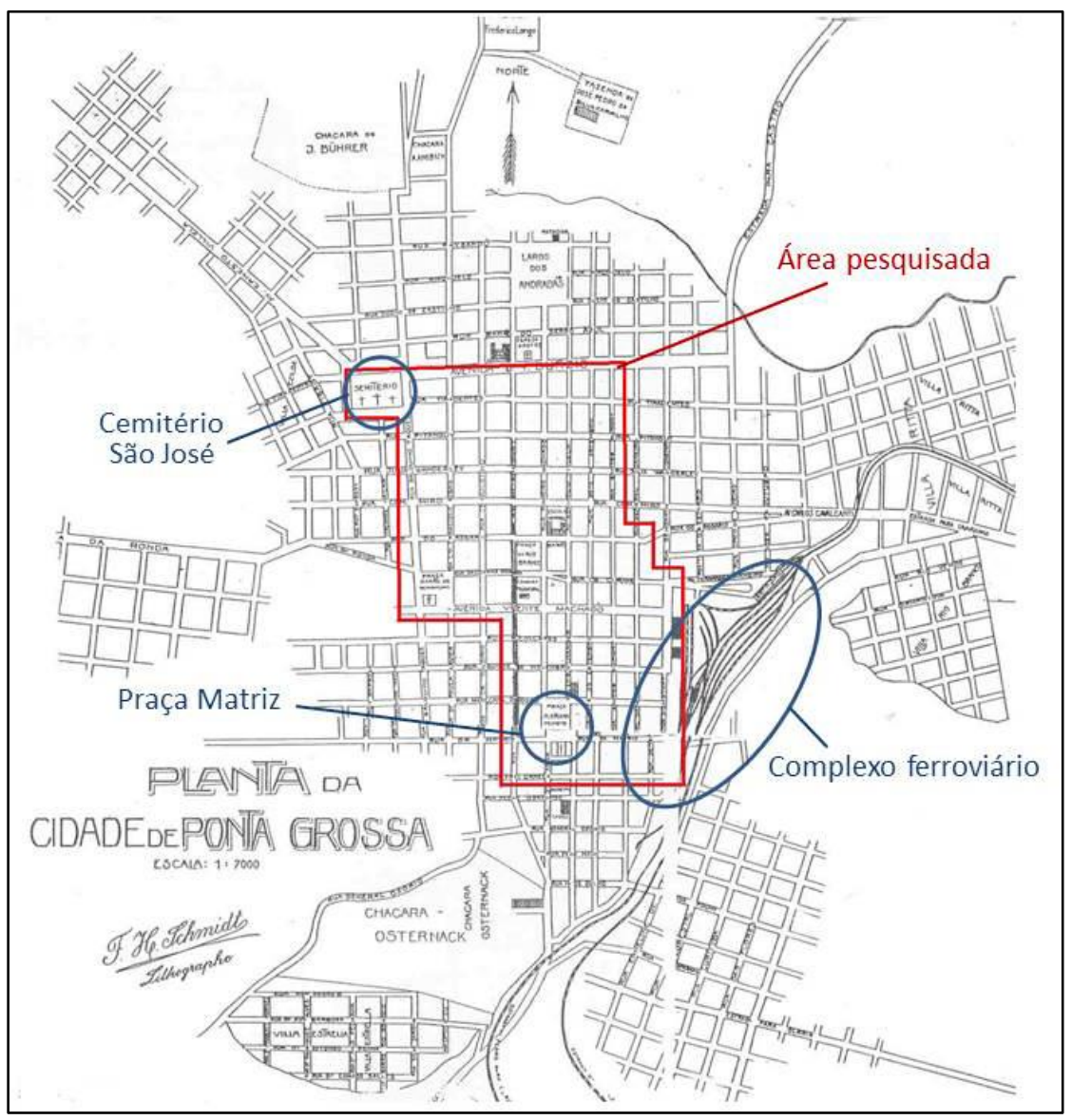

Figura 1. Mapa do município de Ponta Grossa de 1920, utilizado como base deste levantamento. A área pesquisada está indicada em vermelho com destaque para o Complexo Ferroviário, a Praça da Igreja Matriz e o Cemitério São José - principais marcos referenciais desta época.

O tombamento tem em vista a preservação de marcos da vida - o que tem valor para a comunidade sobre o objeto. As estações possuem uma beleza arquitetônica, proporcionando um potencial de uso principalmente cultural aos locais.

A partir da instalação da linha férrea em Ponta Grossa ocorreu um grande desenvolvimento na economia, surgiram oportunidades de trabalho, o transporte de cargas e passageiros tornou-se mais ágil e houve uma profunda alteração na paisagem da cidade. Com a modernização para as construções das estações, foram utilizadas rochas da geodiversidade local, o que acontece até os dias de hoje, com grande variedade em elementos da construção civil, graças principalmente à alta qualidade, durabilidade e/ou baixo custo de algumas destas rochas (ALESSI et al., 2015). A possibilidade de transporte ferroviário, no entanto, permitiu também a vinda de outros materiais rochosos de fontes ao longo do eixo da linha de ferro.

\section{CONTEXTO GEOLÓGICO REGIONAL}

Ponta Grossa é um município que apresenta parte de seu território sobre o Primeiro Planalto
Paranaense, o que significa dizer que as rochas nesta porção são mais antigas (Pré-Cambriano), metamórficas e ígneas em geral, que constituem o Escudo ou Embasamento Cristalino no Paraná (ver Figura 02). Nesta área do Escudo predominam mármores e metacalcários dolomíticos, filitos, quartzitos e gnaisses com mais de 1.1 bilhões de anos e granitos com cerca de 570 milhões de anos (Complexo Granítico Cunhaporanga, Grupos Setuva e Açungui, Suíte de Monzogranitos - MINEROPAR, 2006).

A maior parte do território, no entanto, incluindo a totalidade do núcleo urbano do município, encontra-se sobre o Segundo Planalto Paranaense, caracterizado por rochas sedimentares da Bacia Sedimentar do Paraná (Fanerozoico), cortadas eventualmente por diques e soleiras de diabásio, relacionadas à separação dos continentes (135 milhões de anos). Em Ponta Grossa afloram arenitos da Formação Furnas (Devoniano), folhelhos fossilíferos da Formação Ponta Grossa (Devoniano) e arenitos e diamictitos do Grupo Itararé ligados à glaciação permo-carbonífera (MINEROPAR, 2006). 


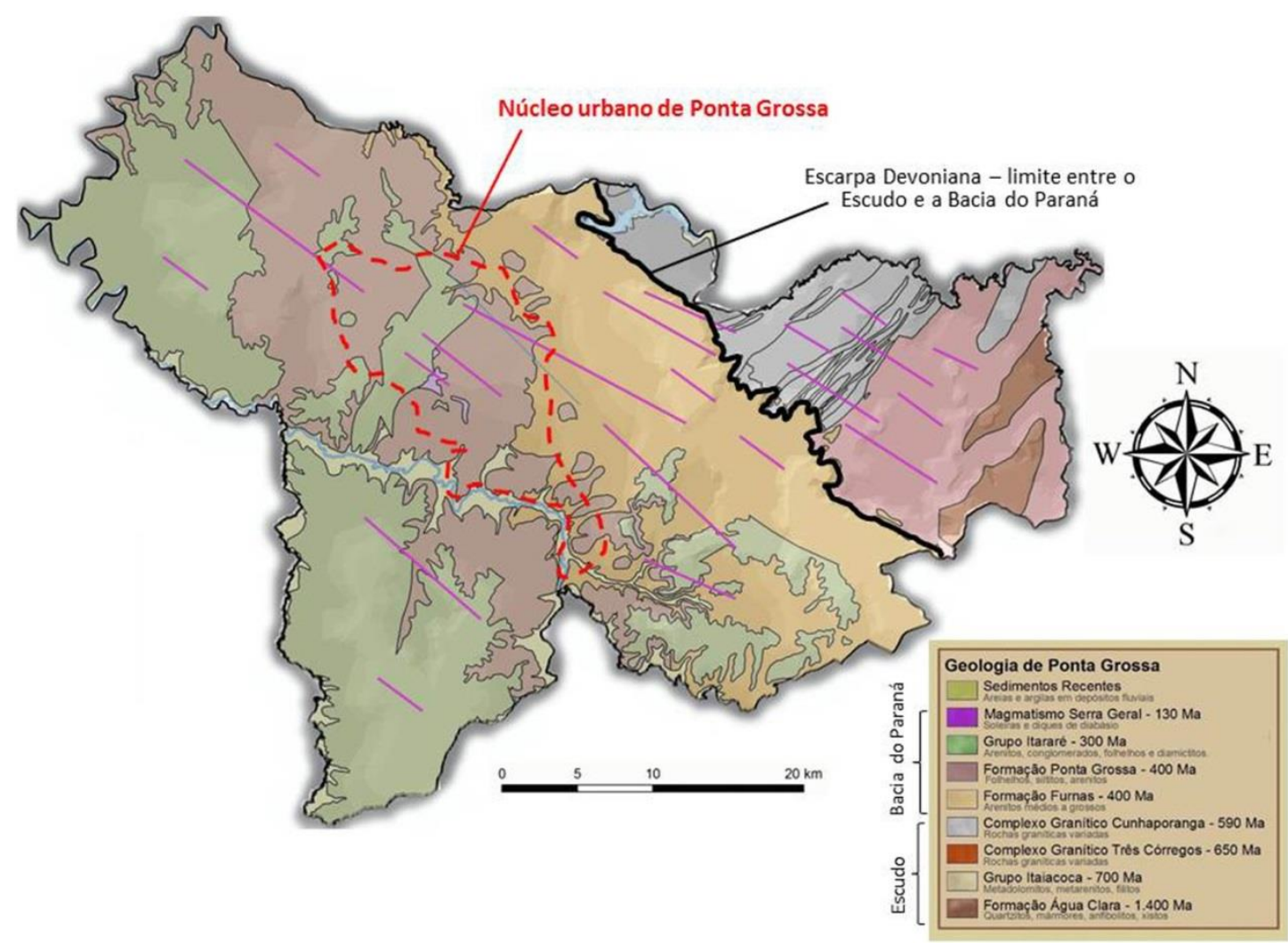

Figura 2. Esboço geológico do município de Ponta Grossa, indicando as principais formações do Embasamento e da Bacia, separados pela Escarpa Devoniana, que marca a separação dos planaltos. Diques de diabásio são representados de maneira esquemática, pois são bastante abundantes e de dimensões variadas - de alguns centímetros até dezenas de metros de largura e de alguns metros até quilômetros de comprimento.

Com muitas fraturas e falhamentos, associados à estruturação do Arco de Ponta Grossa, são abundantes os diques e soleiras de diabásio que são resultado do preenchimento das fraturas (Mesozoico). O diabásio, portanto, é uma das principais rochas de maior resistência mecânica disponível no município.

\section{RESULTADOS}

As edificações e pavimentos analisados dentro da área citada mostraram a predominância das seguintes rochas utilizadas em sua construção: diabásio, metacalcário dolomítico, arenito e granito.

Dentre estes materiais, duas rochas provêm da cidade de Ponta Grossa, de pedreiras próximas, e outras duas vieram de fora, muito provavelmente transportadas por trem. Entre as rochas utilizadas no patrimônio estudado, a principal é o diabásio, que, originada em ambiente magmático, apresenta estrutura maciça, textura granular fina a média e cor que varia do cinza escuro ao preto. Conhecidas como "pedra-ferro", tipicamente encontradas na região, estas rochas se formaram preenchendo fraturas que foram causadas em outras rochas por movimentos geológicos. No estado do Paraná, este processo ocorreu no período Jurássico (Era Mesozoica), há cerca de 135 milhões de anos e este tipo de preenchimento formou estruturas chamadas de dique ou soleira (LICCARDO, 2010). Muito utilizado em calçadas tipo petit pavé (calçada portuguesa) e em construções na cidade de Ponta Grossa, bem como base e sustentação para edificações, como na estação ferroviária, o diabásio tem grande resistência, mas pode sofrer com o intemperismo químico, oxidando-se, e também se forem utilizados produtos de limpeza indevidos. A cor preta a cinza escuro é devida à quantidade de piroxênio e outros minerais escuros presentes $(40 \%$ a 60\%), que são compostos principalmente por ferro, magnésio e cálcio entre outros. $\mathrm{Na}$ composição também se encontram feldspatos em menor quantidade (ALESSI et al., 2015).

Este material forma também escadas e boa parte do conjunto de plataformas do conjunto ferroviário. No período de instalação das estações, a extração de diabásio era feita somente em três pedreiras: Chácara Dantas, Vila Cipa e Vila Odete (ALESSI et al. 2015). Graças à proximidade das fontes houve o barateamento do material, minimizando-se o gasto com transporte. Esta mesma proximidade posteriormente provocou o fechamento destas lavras, já que o avanço do núcleo urbano inviabilizou os trabalhos de extração.

Os materiais de origem local estão muito 
presentes nas edificações, monumentos e calçadas, caracterizando a cidade de maneira particular e tendo grande papel na configuração da paisagem urbana. Muitas ruas de Ponta Grossa são ainda revestidas com poliedros ou paralelepípedos de diabásio.

No conjunto ferroviário foram catalogadas as rochas existentes nas duas estações e no armazém de cargas, sendo elas: 1) Diabásio proveniente da região, rocha principalmente utilizada em pavimentação, meios-fios, alicerces das plataformas e muros de contenção no conjunto; 2) Metacalcário dolomítico, proveniente do Embasamento Cristalino, utilizado em calçamentos tipo mosaico português; 3 ) Granito Rosa, proveniente da Serra do Mar (Escudo), encontrado nas plataformas em grandes blocos que foram entalhados em cantaria, técnica hoje quase extinta; 4) Arenito proveniente do Grupo Itararé, utilizado nos cunhais da estação.

Entre os resultados também foi elaborado um mapa demonstrativo dos três diferentes estilos de calçadas presentes nas ruas mais antigas, de acordo com a disposição, tamanho e formato dos materiais: 1) Mosaico português, mais recente e formado por pequenos blocos poliédricos encaixados, geralmente de diabásio ou metacalcário; 2) Lousas de diabásio, com aproximadamente $20 \mathrm{~cm} \times 20 \mathrm{~cm}$ dispostas de maneira ordenada; 3) Blocos de diabásio, mais antigo e sem organização exata, com disposição assimétrica (Figura 03).

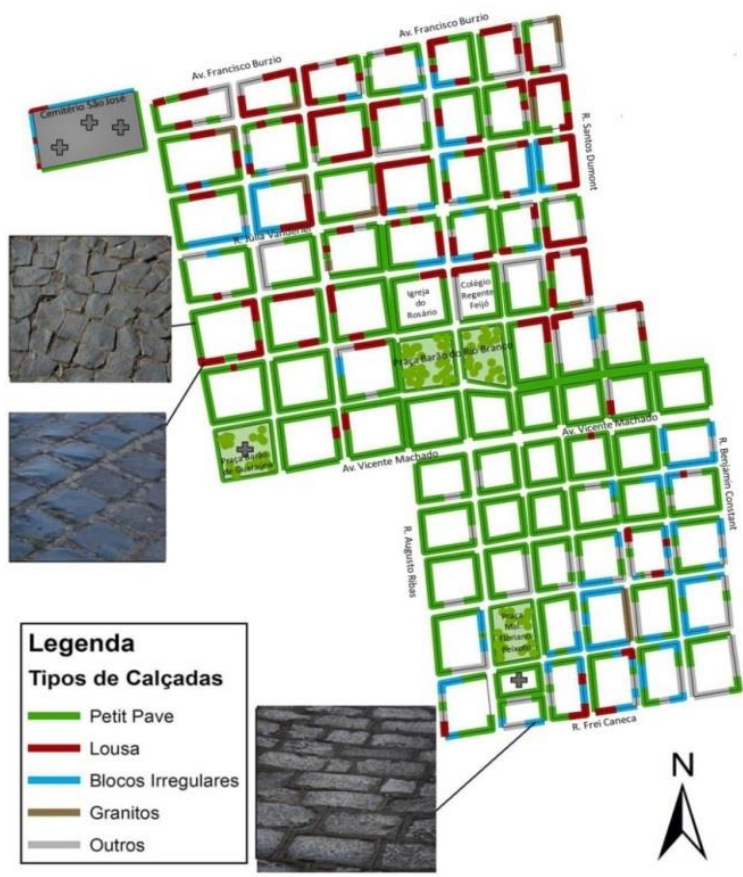

Figura 3. llustração dos tipos de calçamentos encontrados no Centro Histórico de Ponta Grossa e sua localização nas quadras mais antigas da cidade.

Utilizado com acabamento de cantaria (PEREIRA et al., 2008; LICCARDO, 2010; CRISTOFARO, 2016), outra rocha aplicada na estação ferroviária foi o granito. Composto por feldspatos (cerca de 55\%), quartzo (cerca de $30 \%$ ), biotita (10\%) e clorita (5\%), e outros em pequenas quantidades, o granito Rosa Curitiba apresenta características mecânicas diferentes do diabásio (LICCARDO, 2010). Trazido da Serra do Mar pelo trem (distante mais de $150 \mathrm{~km}$ ), é formado em ambiente magmático plutônico, diferentemente do diabásio, resultando na formação de cristais maiores e aparência menos homogênea, com minerais visíveis a olho nu. Esta rocha foi e é amplamente utilizada graças a sua resistência, gerada principalmente pela presença do quartzo, de alta dureza, e por ser menos suscetível aos ataques do intemperismo. $\mathrm{Na}$ plataforma da estação, compunha principalmente o lado em que o trem parava e havia trânsito de cargas, exigindo um material mais resistente como é o granito.

$\mathrm{O}$ arenito do Grupo Itararé também foi utilizado em parte da estrutura da antiga estação. Esta rocha é muito conhecida em Ponta Grossa, graças ao Parque Estadual de Vila Velha em que forma relevos diferenciados. Porém, neste caso foi extraída provavelmente na Lapa (distante cerca de $120 \mathrm{~km}$ ), chegando até o local por um braço ferroviário inexistente hoje. De origem sedimentar, este arenito é formado principalmente por grãos de quartzo com pequena quantidade de silte e argila (MELO, 2006). Sua cor varia de acordo com o sedimento que o formou e vai do bege ao marrom escuro, com forte influência de óxidos de ferro. Por ser uma rocha mais friável, o arenito suporta menos o intemperismo físico e choques mecânicos, mas é um material mais fácil de ser trabalhado em cantarias. Nas construções analisadas já existe um processo de deterioração nas partes formadas por esta rocha, o que exigirá uma difícil reconstituição física do patrimônio.

O metacalcário dolomítico, utilizado nas calçadas estilo petitpavé, associado ao diabásio no entorno da estação, é proveniente de Itaiacoca, distrito pontagrossense situado no Primeiro Planalto. Esta rocha metassedimentar carbonática teve seu uso como poliedros em pavimentos de Ponta Grossa bem posterior ao diabásio, a partir de meados do século $X X$.

Nas estações estudadas ficam nítidos os detalhes em rocha que embelezam a construção, assim como nas calçadas de estilo petitpavê (conhecidas no resto do Brasil como "calçada portuguesa"), em que blocos poliédricos de diabásio e/ou metacalcário são devidamente encaixados, podendo formar, inclusive, desenhos(como araucárias e pinhões entre outros) associados ao movimento paranista (LICCARDO, 2010). A Figura 04 indica detalhes das rochas encontradas nas edificações. 


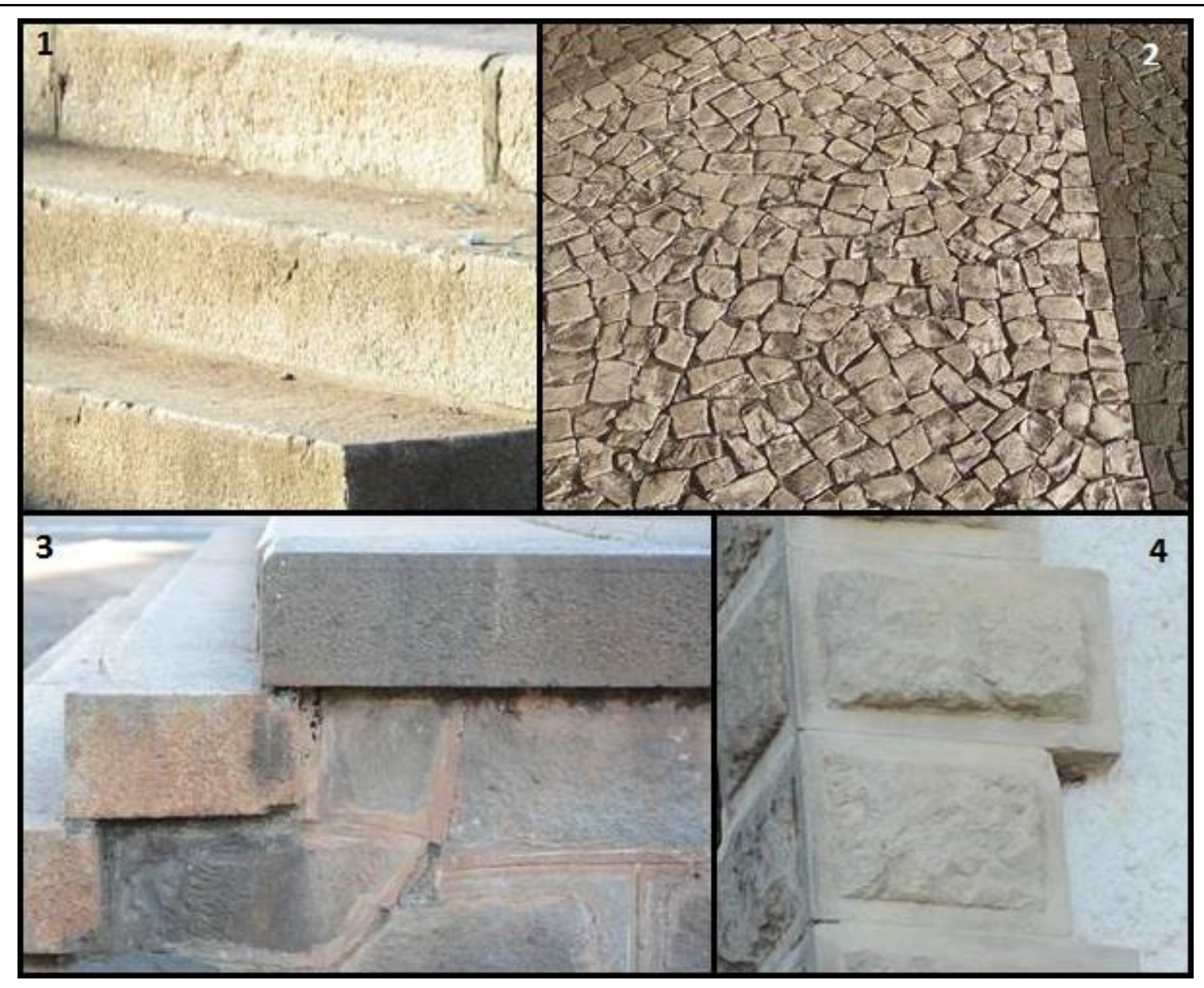

Figura 4.1. Escada de cantaria em diabásio; 2 - Petit pavé de metacalcário dolomítico; 3. Peças de cantaria em granito no terminal de carga de trens; 4. Cunhal da Casa de Memória em arenito. Foto: Alessi

\section{CONSIDERAÇÕES FINAIS}

As rochas mais comumente utilizadas na construção do patrimônio histórico material de Ponta Grossa ofereceram maior durabilidade, o que favoreceu a preservação de muitas calçadas e detalhes das edificações. Este estudo permitiu a indicação da procedência e métodos de transporte das rochas, e apontou, na eventual restauração do patrimônio, a possibilidade de utilização de materiais da mesma área-fonte, mantendo as características originais.

$O$ beneficiamento em geral aplicado às rochas é denominado cantaria, cuja finalidade é talhar e/ou criar acabamentos para uso estrutural ou ornamental. Esta técnica foi utilizada desde as civilizações mais antigas, e os canteiros não somente entalham como fazem o corte e redimensionam o material a ser esculpido (PEREIRA et al., 2008; CRISTOFARO, 2016). Atualmente não existe grande número de canteiros ou mesmo de calceteiros em atividade em Ponta Grossa, pois estes já são considerados ofícios em extinção no Paraná. No entanto, a técnica de cantaria é um dos fatores que mais contribuiu para o tombamento do patrimônio, sendo especialmente crítica a sua ausência nos processos de restauração. Em 2014, a equipe de arquitetura especializada em restauração que deve atuar neste conjunto se deparou com esta dificuldade. Os blocos de arenito que constam na estrutura da estação vieram de pedreiras desativadas e foram talhados com técnicas que hoje poucos dominam (ALESSI et al., 2015). A substituição destes blocos danificados (Figura 05) constitui, por isso, grande desafio para a restauração e a manutenção do patrimônio cultural de Ponta Grossa.

Este conjunto de informações sobre o uso histórico das rochas na construção da cidade de ponta Grossa mostrou-se um interessante campo para a educação patrimonial, desenvolvendo um senso de identidade territorial a partir dos elementos da geodiversidade que constituem o substrato do território e suas aplicações pela sociedade em diferentes tempos. 


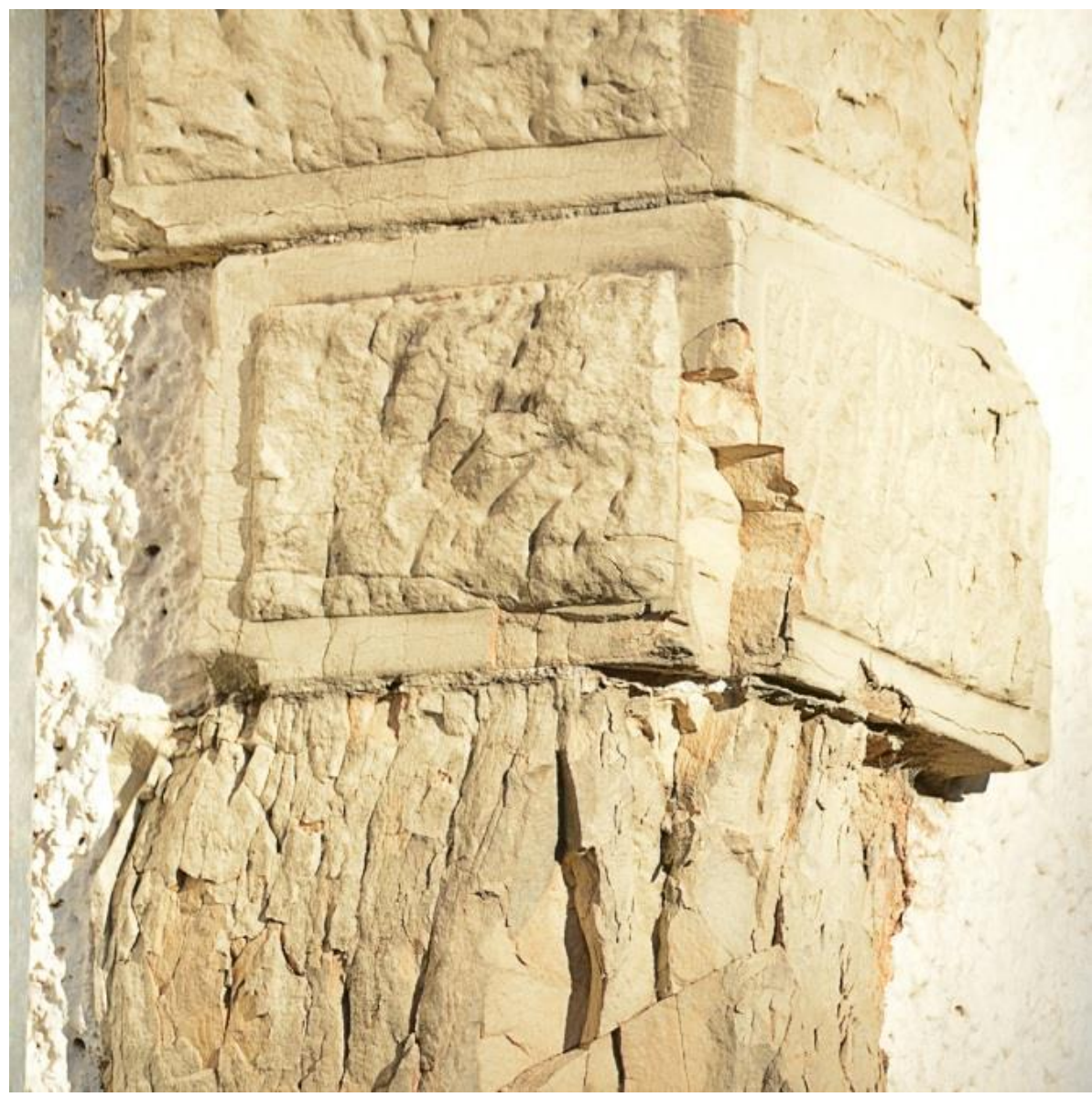

Figura 5. Cunhal de arenito da antiga estação (hoje Casa da Memória de Ponta Grossa) danificado. A necessária substituição envolverá o uso de rochas procedentes da mesma fonte e a técnica de cantaria semelhante ao original. Foto: Liccardo.

\section{REFERÊNCIAS BIBLIOGRÁFICAS}

ALESSI, S.M.; OLIVEIRA, M.; LICCARDO, A. Levantamento da Geodiversidade do Patrimônio Histórico de Ponta Grossa, PR. Anais do 3은 Simpósio Brasileiro de Patrimônio Geológico, Lençóis, Bahia. 2015

CRISTOFARO, R. Trabalhos em pedra e ofício da cantaria em Juiz de Fora e região. Funalfa, 2016. 192p.

GIESBRECHT, R. M. Estações ferroviárias do Brasil. Ponta Grossa (nova). 2014. Disponível em:Acesso em: 21 agosto 2014.

LICCARDO, A. La pietra e L'uomo : Cantaria e Entalhe em Curitiba. São Paulo: BecaBall Edições, 2010. 150 p.

MELO, M. S. Formas rochosas do Parque Estadual de Vila Velha. Ponta Grossa: Editora UEPG, 2006. 145 p.

MINEROPAR. 2006. Produção mineral paranaense por municípios. Disp. em: http://www.mineropar.pr.gov.br. Acesso em: 04 jun. 2014
PEREIRA, C. A.; LICCARDO, A.; SILVA, F. G. A Arte da Cantaria. Belo Horizonte: C/ Arte, 2007. 80p.

Contribuição ao 1‥ Simpósio Brasileiro de Caracterização e Conservação da Pedra 14 a 16 de dezembro de 2016, Congonhas - MG

Nota:

É de responsabilidade da comissão editorial do Simpósio a revisão gramatical, ortográfica, de citações e referências bibliográficas. As normas de submissão podem se diferenciar das desta revista. 